\section{Hernán}

Corral

Talciani

Universidad de los Andes, Chile

hcorral@uandes.cl

Recibido: 24.10.16

Aceptado: 1.12.16

\title{
El derecho al olvido en internet:
} antecedentes y bases para su configuración jurídica

\section{The right to oblivion in Internet: background and bases for its legal configuration}

Resumen: En el último tiempo ha ido ganando terreno el llamado "derecho al olvido" (o el derecho a ser olvidado) por el cual una persona exige eliminar de internet alguna noticia, dato o imagen que, por el transcurso del tiempo, ha perdido actualidad y, sin embargo, sigue siendo fácilmente accesible para cualquiera que consulte por el nombre de la persona aludida. Con una aceptación creciente en el ámbito eurocomunitario, despierta resistencias en los medios anglosajones por el mayor peso que estos suelen conceder a la libertad de expresión. En este trabajo se describe lo que parece ser una evolución de esta figura en tres etapas hasta llegar al actual derecho al olvido en internet o digital, con comentarios a la primera sentencia de la Corte Suprema chilena que afirma la existencia de este derecho como emanación del derecho al respeto de la vida privada y la honra de la persona. Se postula que estamos ante un derecho en fase de formación, pero que no puede ser absoluto, sino que debe compatibilizarse con otros derechos y valores fundamentales para una sociedad democrática. E principio de proporcionalidad (mínima intervención) puede ayudar a determinar las modalidades de aplicación de este derecho para atender a los intereses de quienes quieren "ser olvidados" pero sin perjudicar desproporcionadamente la libertad de expresión y el acceso a la información.

Palabras clave: derecho al olvido, internet, intimidad.
Abstract: In recent times it has been gaining ground the so-called "right to oblivion" (or the right to be forgotten) by which a person requires to remove from Internet somenews, data or image which, over time, has lost topicality without but which continues being easily accessible to anyone who asks for the name of the person referred to. With a growing acceptance at the European Community level, such right provokes resistance in the Anglo-Saxon media by the greater weight the latter often grants to freedom of expression. This paper describes what appears to be an evolution of this figure in three stages up to the current right to oblivion on the Internet or digital, with comments on the first sentence of the Chilean Supreme Court affirming the existence of this right as an emanation of the right to respect a person's private life and honor. It is argued that this right is being formed though it can not be absolute but must be reconciled with other rights and fundamental values of a democratic society. The proportionality principle (minimal intervention) can help determine the ways of implementing this right in order to serve the interests of those who want "to be forgotten" without disproportionately harming freedom of expression and access to information.

Keywords: the right to oblivion, Internet, privacy. 


\section{Planteamiento}

La construcción de un "derecho al olvido" ha estado muy presente en los últimos años debido a una multiplicidad de reclamos de personas que pretenden que ciertas alusiones a sus actuaciones en el pasado sean eliminadas de esta especie de biblioteca universal borgiana en que se ha convertido la red de redes: internet.

Un gran impacto provocó el año 2014 la sentencia del Tribunal de Justicia de la Unión Europea que, contra todo lo previsto, estableció que el buscador digital más importante, Google, tenía la calidad de banco de datos y, por ello, estaba sujeto a la Directiva 95/46/CE, de 24 de octubre de 1995, sobre tratamiento de datos personales, y debía acceder a la petición de un particular de dejar de arrojar como resultados de una búsqueda asociada a su nombre una noticia antigua que le perjudicaba ${ }^{1}$.

Frente a las críticas que hicieron ver que una aplicación indiscriminada de este derecho al olvido, vendría a controlar la libertad de expresión y el derecho a la información en internet y consagrar una especie de "censura retrospectiva", otros pronunciamientos han matizado el ejercicio de esta facultad. El debate se ha reencendido con la aprobación del Reglamento (UE) 2016/679, de 27 de abril de 2016, relativo a la protección de las personas físicas en lo que respecta al tratamiento de datos personales y a la libre circulación de estos datos, que contiene una regulación expresa del "derecho al olvido" (art. 17) y que, a diferencia de la Directiva 95/46/CE, es de aplicación directa en el derecho interno de los Estados de la Unión Europea, si bien sólo entrará en vigencia en 2018.
El problema llegó ya a los estrados judiciales chilenos y fue motivo de la sentencia de la Corte Suprema de 21 de enero de 2016 (Corte Suprema, 21 de enero de 2016, rol № 22.243-2015). Los hechos de este caso pueden ayudar a entender el conflicto jurídico que se produce entre dos derechos fundamentales: el derecho al respeto de la vida privada, por un lado, y la libertad de emitir opinión e informar, por el otro.

El 14 de agosto de 2004 el diario El Mercurio publicó la siguiente noticia: "el Ministro en visita Sergio Muñoz, sometió a proceso al Mayor (I) de Carabineros A.G. ${ }^{2}$, como presunto autor del delito de abusos sexuales contra menores [...] A.G. se desempeñó como Jefe de Contabilidad del Hospital de Carabineros hasta el año 1999 y en la 34a. Comisaría de Menores". Los hechos se asociaban al entonces famoso "caso Spiniak"3. El 8 de septiembre de 2015, A.G. solicita por escrito al representante legal de El Mercurio, Agustín Edwards Eastman, que disponga la eliminación de dicha noticia de los motores de búsqueda del portal de internet EmolEl Mercurio on line, dependiente del diario. La empresa le contesta pidiendo que presente documentos válidos que constaten que ha sido sobreseído o absuelto y que firme una renuncia al ejercicio de acciones judiciales en contra del diario. No conformándose con esta respuesta, el afectado recurre de protección ante la Corte de Apelaciones de Santiago, por vulneración del derecho a la integridad psíquica (art. $19 \mathrm{~N}^{\circ} 1$ Const.) y del derecho a la honra y la vida privada, suya y de su familia (art. $19 \mathrm{~N}^{\circ}$ 4 Const.). Expone que la mantención en internet de esa

\footnotetext{
${ }^{1}$ TJUE, sentencia de 13 de mayo de 2014, Google Spain S.L. y Google Inc. contra Agencia Española de Protección de Datos (AEPD) y Mario Costeja González, C131/12, disponible en /document/document.jsf?docid=152065\&doclang=ES (consulta 20 de octubre de 2016). ${ }^{2}$ No incluimos el nombre del recurrente para evitar contribuir al llamado "efecto Streisand", según el cual los que recurren a la justicia buscando protección a la intimidad pueden obtenerla, pero a costa de ver incrementados los niveles de difusión y publicidad de su caso. El título proviene de una demanda de la actriz y cantante Barbra Streisand pidiendo que se retirara de internet una fotografía de su casa en Malibú que hasta entonces había tenido muy pocas visitas o descargas, y que después de la publicidad que se dio al juicio llegó a tener más de 400.000 visitas al mes: cfr. Anguita (2016), 209-210.

${ }^{3}$ Se trató de un juicio por delitos de estupro, prostitución infantil y producción de material pornográfico cuyo principal inculpado era un empresario, al que se le atribuían redes de abuso de menores en las que aparecían implicados políticos de renombre, lo que más tarde se reveló falso. El inicio del caso data del año 2003. A.G. fue condenado con 541 días de pena remitida como autor del delito de abuso sexual por sentencia del 31 de diciembre de 2010 del 34 Juzgado del Crimen de Santiago en causa rol № 214.724- 2004, confirmada por la Corte de Apelaciones de Santiago por sentencia de 9 de mayo de 2011, rol № 616-2011.
} 
noticia no le permite su reinserción en la vida social en paz, al resultar estigmatizado con la información, afectando con ello no sólo a su persona, sino que también a toda su familia.

El diario recurrido informa que no es posible acceder a la petición de A.G. ya que de hacerlo se estaría vulnerando la libertad de información, base del ejercicio del periodismo. Por el contrario, la publicación en internet estaría amparada por el art. 19 № 12 de la Constitución, que consagra la libertad de emitir opinión y de informar, sin censura previa.

Dejamos en suspenso la forma en la que las Cortes resolvieron el tema, para analizar brevemente cómo se ha ido construyendo esta figura denominada derecho al olvido (II) y cuáles han sido las sentencias más relevantes que han dado forma a su versión en internet (III). Con esos antecedentes, volveremos a la sentencia de la Corte Suprema chilena (IV), para luego abocarnos a un intento de configuración del derecho al olvido en general $(V)$ y del derecho al olvido en particular (VI). Finalmente, haremos unas breves reflexiones sobre las perspectivas de futuro en la aplicación digital de este nuevo derecho (VII).

Nos proponemos mostrar cómo el derecho al olvido ha ido evolucionando desde los primeros años del siglo XX y cómo con la expansión de internet ha ido cristalizando en un nuevo derecho subjetivo, derivado del derecho a la vida privada, y cuyo ejercicio debe admitirse sólo en la medida que menos lesión produzca a las libertades de expresión y de empresa. En todo caso, no pretendemos sino ofrecer una mirada panorámica del tema y aportar algunas reflexiones, todavía muy aproximadas, sobre lo que nos parece debiera ser la configuración jurídica de este novedoso derecho.

\section{Derecho al olvido: un concepto desarrollado en tres etapas}

\subsection{El derecho al olvido en los medios}

Los orígenes del derecho al olvido pueden remontarse a las primeras décadas del siglo $X X$, cuando la prensa y otros medios de comunicación adquieren el impacto masivo que los ha caracterizado y, en cierta manera, va de la mano de la configuración progresiva del "right to privacy" que emerge en el sistema jurídico estadounidense pero que se expande rápidamente a otros ordenamientos, tanto americanos como europeos (De Terwangne, 2012) .

De esta manera, cuando en 1960 William Prosser sistematiza los casos de torts por violación de la privacy que había producido el clásico artículo de 1890 publicado por Warren y Brandeis en Harvard Law Review (Warren \& Brandeis, 1890), identificará cuatro categorías: la intrusión en el ámbito privado de la víctima, la difusión de hechos de su vida privada, la publicación que la coloca en una falsa luz a los ojos del público y la apropiación de las ventajas que provienen del uso de su nombre o apariencia (Prosser, 1960). Casi al final del artículo, Prosser trata del problema de volver a traer a la publicidad hechos del pasado dentro del marco de las limitaciones al privilegio de la prensa de informar sobre hechos privados de figuras públicas. Se plantea entonces lo que llama una "troublesome question" - pregunta complicada - todavía no completamente resuelta y que consiste en los efectos del paso del tiempo cuando quien fuera una figura pública ha retornado al anonimato. En principio, Prosser piensa que debe prevalecer el derecho de la prensa a informar y que de las decisiones judiciales puede desprenderse que "una vez que un hombre se ha vuelto figura pública o noticioso, permanece como material de legítimo recuerdo para la mente del público hasta el final de sus días" (Prosser, 1960, p. 418).

\footnotetext{
${ }^{4}$ De Terwangne (2012), p. 55, caracteriza esta primera etapa del derecho al olvido como "el derecho al olvido del historial judicial". Nos parece que la denominación es poco apropiada porque los casos en los que se plantea no siempre son de noticias penales o judiciales y, además, porque lo relevante es cómo se actualiza el pasado que se quiere olvidar, y en estos casos es a través de una nueva publicación en los medios de comunicación no digitales.
} 
Sin embargo, Prosser destaca algunos casos en los que los tribunales estadounidenses han considerado que la fama o lo noticioso de alguien no legitima volver a traer a la palestra hechos del pasado. El más importante de estos casos es, sin duda, Melvin v. Reid, juicio por el cual una mujer que en el pasado había ejercido la prostitución y había sido acusada de homicidio, pero que luego de ser perdonada llevó por años una vida tranquila y anónima en otro lugar, reclamó contra el productor de la película The Red Kimono (1925) que revelaba su historia. La Corte dio la razón a la demandante, diciendo que toda persona que lleva una vida recta debe verse libre de ataques innecesarios a su reputación (Melvin v. Reid 112 Cal. App. 285, 297 Pac. 91, 1931).

Sobre la base de este caso, y otros similares, se hablará de un right to be forgotten, expresión que parece haberse tomado del francés: droit à l'oubli (Rossen, 2012) pero con muchas más aprehensiones que en el ámbito europeo. De hecho, después de Melvin v. Reid, se suele citar un caso en el que se falló a favor de la libertad de expresión: Sidis v. FR Publishing Corp (1940). En el caso una persona que en su niñez había ganado fama como "superdotada" pero que de adulto hacía una vida tranquila y alejada de los medios, demandó al The New Yorker por publicar un reportaje sobre su historia. La Corte, en este caso, sostuvo que el derecho a controlar la propia vida puede ser limitado por el valor social de que los hechos sean públicos (Sidis v. F-R Publishing Corporation 311 U.S. 711 61, 1940 U.S.).

En Europa se mencionan como antecedentes del derecho al olvido la sentencia del Tribunal de Gran Instancia de Sena (4 de octubre de 1965) que resolvió la demanda de una de las amantes del famoso asesino en serie Henri Landru, por haber sido representada en una película después de muchos años de su relación con el homicida (T.G.I. Seine, 1965) ${ }^{5}$. En Alemania se suele considerar como antecedente la decisión del Tribunal Constitucional que estimó que no debía exhibirse un reportaje televisivo que mencionaba a un convicto de robo y homicidio, que estaba por cumplir la pena de seis años de presidio que se le había impuesto ${ }^{6}$.

Nótese que en estos casos lo que sucede es que una nueva publicación saca a relucir hechos del pasado de la persona que habían sido difundidos en los medios. Esto, por cierto, puede seguir sucediendo, pero el derecho al olvido adopta una nueva faceta con la aparición de los bancos o servicios de tratamiento de datos personales. Ahora, ya no se trata de una nueva noticia que se refiere al pasado, sino de la mantención de informaciones que fueron incorporadas legalmente hace muchos años pero que, gracias a este tipo de bases, permanecen siendo accesibles con relativa facilidad por los usuarios de dichos bancos de datos. El problema se intensifica cuando estas bases de datos utilizan las tecnologías de la informática, y aparecen los sistemas de procesamiento o tratamiento de datos personales ${ }^{7}$.

2.2. El derecho al olvido en los sistemas de procesamientos de datos

Contrariamente a lo que pudiera parecer, la preocupación por la permanencia de información recogida en registros que podría ser perjudicial para las personas después de transcurrido un tiempo, es antigua, incluso anterior a la aparición de las modernas bases de datos informáticas. Dos son las áreas en las que se manifiesta la idea de que puedan eliminarse informaciones para evitar perjuicios que se consideran indeseables socialmente: la primera, es el área penal y la segunda, es el área comercial.

La preocupación por la reinserción de personas que han sido condenadas y la eliminación de antecedentes penales data de principios del siglo XX. En Chile, en plena República socialista, se dictó el D.L. 409, de 12 de agosto de 1932, por el cual se permitió que toda persona que haya sido condenada penalmente, después de cumplir la pena y siempre que haya transcurrido un plazo mínimo

\footnotetext{
${ }^{5}$ La sentencia habla de "prescripción del silencio" y en definitiva rechaza en este aspecto la demanda ya que la actora había publicitado su relación con Landru. En el comentario de Lyon-Caen se habla por primera vez del "droit a l'oublie" como posible fundamento de la demanda.

${ }^{6}$ Sentencia de 5 de junio de 1973, BVerfGE 35, 202, traducción al inglés disponible en http://www.iuscomp.org/gla/judgments/tgcm/ v730605.htm (consulta 19 de octubre de 2016).

${ }^{7}$ Cfr. Uicich (1999), pp. 39-58; Novoa (1989), pp. 106-109.
} 
de dos o cinco años, pida que, por decreto supremo, se la considere "como si nunca hubiera delinquido para todos los efectos legales y administrativos" (art. 10).

En el ámbito de la información comercial, económica o financiera debemos remontarnos al año 1928 cuando se dicta el Decreto Supremo № 950, Ministerio de Hacienda, de 28 de marzo de dicho año, por el cual se encarga a la Cámara de Comercio de Chile (hoy Cámara de Comercio de Santiago A.G.), la elaboración de un boletín semanal con la sistematización de las informaciones que se ordena a diversas instituciones (tribunales de justicia, notarías, conservadores, bancos y sociedades financieras) enviar regularmente a ese organismo. Aparece así el Boletín Comercial que se mantiene hasta nuestros días. En su texto original, el Decreto № 950 contemplaba lo que hoy llamaríamos derecho al olvido, ya que sin perjuicio de las "aclaraciones" que pudieran hacer los afectados, se disponía que las publicaciones aparecidas en el Boletín Comercial dejarán de tener vigencia transcurridos más de cinco años desde que fueron publicadas (art. 10, D. Sup. № 950, de 1928) ${ }^{8}$.

Una vez que la tecnología informática permite el almacenamiento y el manejo de millones de datos personales, entran en escena los bancos de datos computacionales, tanto públicos como privados. En la década de los noventa del siglo pasado comienza a manifestarse la preocupación por regular esta nueva actividad y tratar así de impedir o sancionar los abusos contra los derechos de las personas en que estos bancos de datos pueden incurrir, sobre todo en Europa. Es así como el Parlamento Europeo y el Consejo aprueban la Directiva 95/46/EC relativa a la protección de las personas físicas en lo que respecta al tratamiento de datos personales y a la libre circulación de estos datos $^{9}$. Estas legislaciones conceden una serie de derechos a las personas que son titulares de los datos, y cuya reclamación judicial se ha solido denominar "habeas data" (como parangón al recurso de amparo o habeas corpus). Entre ellos está el derecho de pedir la cancelación o bloqueo de los datos, facultad que, con adecuaciones interpretativas, puede servir para satisfacer las necesidades planteadas por el derecho al olvido. Debe considerarse que, en cambio, en Estados Unidos se ha optado por regulaciones sectoriales según la naturaleza y fuente de los datos, sin que exista una legislación omnicomprensiva ${ }^{10}$.

En Chile, la No 19.628, de 1999, aunque lleva por título "Sobre protección de la vida privada", en realidad sólo se dedica a regular el procesamiento de datos. En esta ley se contienen varios derechos de las personas que son reclamables ante los tribunales respecto de los responsables de bancos de datos, entre ellos el de pedir la eliminación o cancelación de un dato personal. El art. 12 inc. $3^{\circ}$ dispone que "Sin perjuicio de las excepciones legales, podrá, además, exigir que se eliminen, en caso de que su almacenamiento carezca de fundamento legal o cuando estuvieren caducos".

Esta ley reguló también las anotaciones por obligaciones comerciales incumplidas realizadas en el Boletín Comercial, ahora recopiladas y tratadas computacionalmente por empresas privadas como DICOM S.A. Una reforma del año 2002, llevada a cabo por la ley № 19.812, estableció un plazo para la vigencia de esos datos: "En ningún caso pueden comunicarse los datos a que se refiere el artículo anterior, que se relacionen con una persona identificada o identificable, luego de transcurridos cinco años desde que la respectiva obligación se hizo exigible.- Tampoco se podrá continuar comunicando los datos relativos a dicha obligación después de haber sido pagada o haberse extinguido por otro modo legal" (art. 18).

Sin embargo, la regulación tiene limitaciones para que pueda ser eficazmente utilizada en protección al derecho

\footnotetext{
${ }^{8}$ Sobre esta regulación y su desarrollo posterior, puede verse a Anguita (2007), 375-396.

${ }^{9}$ Debe dejarse constancia que ya en la década de los setenta se habían dictado cuerpos legales en ese sentido: en 1973, ley sueca y en 1977, ley alemana. Además, en 1981 se había aprobado, como fruto del trabajo del Comité de Ministros del Consejo de Europa, el Convenio № 108 para la Protección de las Personas con respecto al tratamiento automatizado de datos de carácter personal. Cfr. Anguita (2007), 62-63.

${ }^{10}$ Sobre las diferencias entre el sistema europeo de regulación de datos y el régimen estadounidense, puede verse a Schwartz (2013), 1974 y ss.
} 
al olvido. Estas han sido puestas de relieve por Anguita: la exclusión del ámbito de su aplicabilidad de los medios de comunicación social (art. $1^{\circ}$ inc. $1^{\circ}$ ley $N^{\circ} 19.628$, de 1999) y la ausencia de una autoridad administrativa ante quien los afectados puedan reclamar. A pesar de que la ley permite a las personas afectadas demandar ante un juez de letras en lo civil la eliminación, modificación o bloqueo de los datos, con indemnización de los perjuicios (art. 23 ley № 19.628), los litigantes han preferido utilizar la vía de la acción constitucional de protección por vulneración del art. 19 NN$^{\circ} 4$ de la Constitución (Anguita, 2016).

Pareciera, sin embargo, que la notoriedad que ha alcanzado el derecho al olvido podría producir que las nuevas leyes, o las modificaciones de las leyes vigentes, contemplen expresamente este derecho y otorguen herramientas judiciales eficaces para su protección.

En este sentido, cabe destacar que la Directiva Europea será derogada y sustituida por el Reglamento (UE) 2016/679 del Parlamento Europeo y del Consejo de 27 de abril de 2016 relativo a la protección de las personas físicas en lo que respecta al tratamiento de datos personales y a la libre circulación de estos datos. Este Reglamento contiene un art. 17 que se titula "derecho de supresión", con el añadido entre paréntesis de la expresión: "derecho al olvido". En dicho precepto se establece que el interesado tendrá derecho a obtener del responsable del tratamiento de datos la supresión de un dato en varios casos, entre los cuales se encuentra el que "los datos personales ya no sean necesarios en relación con los fines para los que fueron recogidos o tratados de otro modo" (art. 17.1, a). Pero debe aclararse que el Reglamento, que tiene efecto directo en los países de la Unión Europea y no necesita de trasposición como las directivas, entrará en vigor sólo el 28 de mayo de 2018, según lo prescribe su art. 94.1.

\subsection{El derecho al olvido en internet}

Con la aparición en escena de internet, el derecho al olvido ha conocido una nueva forma de aplicación. Son múltiples los medios (plataformas de videos, como
YouTube, redes sociales como Facebook, Twitter, Instagram, páginas web, blogs, hemerotecas digitales) en los que cuales puede mantenerse indefinidamente una información, imagen, video u otro registro relativos al pasado de una persona, incluso porque ella misma voluntariamente los ha "subido" a la red, pero que más tarde quisiera que se eliminaran de esta exposición online porque los considera lesivos o perturbadores para el estilo de vida que ahora desarrollan.

Esta accesibilidad se ha potenciado más aún con la aparición de los llamados motores de búsqueda (web search engines) que enlazan los sitios web que se refieren a un determinado hecho o individuo para luego sugerirlos en un listado en orden de relevancia para que el usuario pueda ubicarlos fácilmente. El más famoso de estos motores de búsqueda es Google, tanto que se habla ya de "googlear" a una persona para conocer las informaciones que se encuentran en internet respecto de ella ${ }^{11}$. Pero no es el único buscador: también puede mencionarse a Yahoo, Bing y Baidu, aunque actualmente estos no alcanzan al 30\% del mercado, mientras el gigante Google tiene el $70 \%{ }^{12}$.

No parece extraño, en consecuencia, que el derecho al olvido haya adquirido una nueva modalidad de aplicación: permite exigir que las diversas plataformas de la web eliminen información del pasado de alguna persona que, aunque siendo veraz y legítimamente obtenida, se considera que, tras el transcurso de un tiempo, ha devenido en inútil para el público y perjudicial para el interesado. Pero la cuestión se vuelve especialmente compleja cuando la noticia, imagen o video está siendo reproducida a la vez por múltiples fuentes de la web, de modo que eliminarla de alguna de ellas no implica su desaparición en la red, sobre todo que, con la asistencia de los motores de búsqueda como Google, se podrá seguir accediendo a los otros sitios web o plataformas en línea donde la información lesiva se mantiene. Por ello, se presenta el problema de si la persona afectada puede ejercer el derecho al olvido no sólo de la fuente directa en la que aparece la noticia en internet, sino de

\footnotetext{
${ }^{11}$ Sobre Google y su enorme expansión, puede verse a Anguita (2016), 23-27.

12 La información a septiembre de 2016 está disponible en https://www.netmarketshare.com/search-engine-market-share. aspx?qprid=4\&qpcustomd=0\&qpsp=2016\&qpnp=1\&qptimeframe=Y (consulta 11 de octubre de 2016).
} 
los resultados que se obtengan de las búsquedas de los motores que enlazan dichas fuentes al nombre de una persona.

Ha sido este el problema más complejo que, de alguna manera, ha lanzado a la fama en todo el mundo, y con mucha polémica, el derecho al olvido, ya que respecto de las fuentes directas podía aplicarse, convenientemente adaptada, la regulación del derecho a la cancelación de datos personales. Pero, ¿pueden considerarse los motores de búsqueda en internet como responsables de tratamientos de datos personales si ellos no proveen de la información, sino que dirigen a la persona a las direcciones web que son las que contienen directamente los datos?

Este fue el problema que dio lugar a la sentencia más famosa y controvertida sobre la actual versión del derecho al olvido, y que pasamos a examinar en el siguiente apartado referido a los hitos jurisprudenciales que se producen a partir de ella.

\section{Hitos jurisprudenciales}

El juicio que ha devenido en un punto de inflexión en la materia se ventiló en el Tribunal de Justicia de la Unión Europea. Se trata del llamado "caso Costeja", cuyos hechos principales pasamos a reseñar.

Un español, Mario Costeja González ${ }^{13}$, presentó ante la Agencia Española de Protección de Datos, un requerimiento en contra del diario La Vanguardia de Cataluña y Google (tanto Google Spain como Google $I n c .{ }^{14}$ ) a fin de que eliminaran anuncios relativos a una subasta de sus bienes por deudas previsionales que se habían publicado en 1998. La Agencia rechazó el reclamo contra el diario La Vanguardia, pero acogió el referido a Google.

Las dos empresas Google recurrieron contra esta resolución para ante la Audiencia Nacional, la que suspendió el procedimiento y procedió a consultar al Tribunal de Justicia de la Unión Europea si el buscador podía considerarse como responsable de tratamiento de datos personales en los términos de la directiva europea y si, siendo así, estaba obligado a eliminar los enlaces a la noticia sobre la que el demandante pedía ejercer los derechos de cancelación o bloqueo de datos contemplados en dicha normativa.
El informe del Abogado General, el finlandés Niilo Jääskinen, fue del parecer que Google no debía considerarse controlador responsable de un banco de datos bajo la directiva europea y que no cabía un "derecho al olvido" dentro de los derechos protegidos por dicha directiva (Jääskinen, 2013 passim).

Sin embargo, el Tribunal, por sentencia de 13 de mayo de 2014 (C-131/12 ${ }^{15}$ ), determinó que la actividad de un motor de búsqueda, que consiste en hallar información publicada o puesta en Internet por terceros, indexarla de manera automática, almacenarla temporalmente y, por último, ponerla a disposición de los internautas según un orden de preferencia determinado, cuando esa información contiene datos personales, es una actividad de tratamiento de datos y el gestor de búsqueda es un "responsable" de ese tratamiento, que se regulan bajo la directiva europea.

En aplicación de la directiva sostiene, además, que un gestor de un motor de búsqueda está obligado a eliminar de la lista de resultados obtenida tras una búsqueda efectuada a partir del nombre de una persona vínculos a páginas web, publicadas por terceros y que contienen información relativa a esta persona, también en el

\footnotetext{
${ }^{13}$ No ocultamos su nombre porque ha devenido en una celebridad en España y en el mundo.

${ }^{14}$ Hay que señalar que, como toda trasnacional, Google tiene una sociedad matriz: Google Inc., con sede en Mountain View, California (EE.UU.), y oficinas locales que pueden tener personalidad jurídica como agencias o sociedades conforme al derecho interno del país donde operan. En Chile, el 2015 comenzó a operar el primer centro de datos de Google para Latinoamérica. Hay que tener en cuenta que Google Inc. forma parte de la macro-organización de servicios de internet, denominada Alphabet Inc, de reciente creación (2015).

${ }^{15}$ Google Spain SL, Google Inc. v. Agencia Española de Protección de Datos, Mario Costeja González, disponible en http://curia.europa. eu/juris/document/document.jsf?docid=152065\&doclang=ES (consulta 15 de octubre de 2016).
} 
supuesto de que este nombre o esta información no se borren previa o simultáneamente de estas páginas web, y, en su caso, aunque la publicación en dichas páginas sea en sí misma lícita.

Finalmente, resuelve que existe un derecho de la persona, no sujeto a la prueba de un perjuicio, a solicitar que la información de que se trate ya no se ponga a disposición del público en general mediante su inclusión en una lista de resultados, y que este derecho prevalece, en principio, no solo sobre el interés económico del gestor del motor de búsqueda, sino también sobre el interés de dicho público en acceder a la mencionada información.

Afirmado el derecho, establece también la excepción: "Sin embargo, tal no sería el caso si resultara, por razones concretas, como el papel desempeñado por el interesado en la vida pública, que la injerencia en sus derechos fundamentales está justificada por el interés preponderante de dicho público en tener, a raíz de esta inclusión, acceso a la información de que se trate" (n 99).

No se limitó el Tribunal a establecer estos criterios generales, sino que se pronunció sobre el litigio que motivó la sentencia, y consideró que "teniendo en cuenta el carácter sensible de la información contenida en dichos anuncios [los de subasta de bienes por deudas de seguridad social] para la vida privada de esta persona y de que su publicación inicial se remonta a 16 años atrás, el interesado justifica que tiene derecho a que esta información ya no se vincule a su nombre mediante esa lista..." , de modo que en la medida en que en el caso de autos no parecen existir razones concretas que justifiquen un interés preponderante del público en tener acceso a esta información en el marco de tal búsqueda, lo que no obstante incumbe comprobar al órgano jurisdiccional remitente [la Audiencia Nacional de Madrid], el interesado puede, en virtud de los artículos 12, letra b), y 14, párrafo primero, letra a), de la Directiva 95/46, exigir que se eliminen estos vínculos de la lista de resultados" ( $\left.n^{\circ} 98\right)$.

La conmoción que causó la sentencia fue mayúscula, porque no se esperaba un pronunciamiento tan favorable al derecho al olvido, aplicado no ya a las fuentes de origen, sino a los motores de búsqueda de información en internet. Google se quejó amargamente, pero finalmente, el 29 de mayo de 2014, se avino a cumplir la sentencia incorporando en la sección políticas de privacidad de su página web, una respuesta a una "pregunta frecuente", por la que señala que en aras de dar cumplimiento a dicha sentencia pide a los solicitantes que llenen un formulario para que pueda ser evaluado por la empresa, la que eliminará la referencia si "los resultados mostrados deben considerarse inadecuados, irrelevantes o ya no relevantes, o excesivos" ${ }^{\prime 16}$. Son miles las solicitudes que se han recibido. Después de más de dos años de la sentencia el mismo Google reporta que en toda Europa se han eliminado enlaces a 566.444 URLs de un total de 1.720.608 solicitudes, lo que revela que sólo son aceptados los retiros en un $43,2 \%{ }^{17}$.

Sin embargo, estas medidas no han convencido a quienes defienden el derecho al olvido, porque Google sólo aplica el retiro a los servidores locales: Google. es; Google.fr, etc. Ahora, la Comisión Nacional de la Informática y de las Libertades de Francia (CNIL) ha ordenado a Google extender su política a todo el mundo: se habla de un derecho al olvido global o universal y en francés de un "droit au déréférencement". Por resolución de 10 de marzo de 2016, el CNIL cursó una multa de 100.000 euros a Google por no haber acatado esa orden ${ }^{18}$. Google ha reclamado la resolución para ante el Consejo de Estado.

En España, después de que la Audiencia Nacional aplicara el derecho al olvido al señor Costeja (SAN 5129/2014, de 29 de diciembre), la cuestión se ha complicado por una divergencia entre la sala civil y la sala contencioso-administrativa del Tribunal Supremo. Esta última, con fecha 14 de marzo de 2016, anuló resoluciones de la Agencia Española de Protección de Datos que ordenaban acoger solicitudes del derecho al olvido a Google Spain, por considerar que el responsable del tratamiento de los datos no era la filial española sino la matriz Google Inc., con sede en

\footnotetext{
${ }^{16}$ Disponible en https://www.google.com/intl/es/policies/faq/ (consulta 11 de octubre de 2016).

17 Informe disponible en https://www.google.com/transparencyreport/removals/europeprivacy/?hl=es (consulta 11 de octubre de 2016).

${ }^{18}$ La resolución puede descargarse en el sitio web del Cnil: https://www.cnil.fr/fr/droit-au-dereferencement-la-formation-restreinte-de-lacnil-prononce-une-sanction-de-100000-eu (consulta 10 de octubre de 2016).
} 
California, EE.UU. (STS 574/2016). Pero menos de un mes después, la Sala Civil del mismo Tribunal, falló por sentencia de 5 de abril de 2016, que Google Spain sí debe considerarse responsable del tratamiento de datos frente a las demandas de indemnización de perjuicios por afectación de la honra y otros derechos fundamentales (STS 210/2016). No obstante, la sala contenciosoadministrativa ha dictado dos nuevas sentencias, con fecha 13 de junio de 2016, perseverando en su criterio (STS 1381/2016 y STS 1387/2016).

Aparte de los buscadores en internet, también se han presentado demandas fundadas en el derecho al olvido en contra de lo que en España llaman "hemerotecas digitales" y que consisten en archivos informáticos que guardan los medios de prensa de las noticias, reportajes y demás material publicado, y que pueden consultarse con sus propios motores de búsqueda a través de la web.

En este ámbito, puede destacarse la sentencia de 15 de octubre de 2015 (STS 4132/2015), por la cual el Tribunal Supremo español debió pronunciarse sobre un recurso de casación presentado en contra de la sentencia de segunda instancia que había acogido la demanda de dos personas naturales interpuesta en contra de Ediciones El País SL (propietaria del diario El País) que exigía que se eliminara de su hemeroteca digital una noticia que informaba de la detención de los demandados por tráfico de drogas en los años 80 del siglo XX. El Tribunal estimó, al contrario de las sentencias de instancia, que la información era lícita y veraz en su momento, pero que por el transcurso del tiempo podría ser que el tratamiento de dichos datos ya no sea adecuado a la finalidad por la cual fueron recogidos, ya que "un tratamiento que inicialmente pudo ser adecuado a la finalidad que lo justificaba puede devenir con el transcurso del tiempo inadecuado para esa finalidad, y el daño que cause en derechos de la personalidad como el honor y la intimidad, desproporcionado en relación al derecho que ampara el tratamiento de datos". Pero el Tribunal valora también la libertad de expresión y de información y señala que el derecho al olvido no puede amparar que "cada uno construya un pasado a su medida" ni justifica que "aquellos que se exponen a sí mismos públicamente puedan exigir que se construya un currículo a su gusto". En cambio, no tratándose de una persona pública ni de hechos que tengan relevancia histórica, el derecho sí ampara que pueda oponerse al tratamiento de datos personales para evitar que hechos del pasado que pueden estigmatizarlo puedan ser ubicados mediante una simple consulta a un buscador generalista de internet, en vista que el daño es desproporcionado frente a la libertad de información de una hemeroteca digital cuya importancia es secundaria respecto de la edición del diario en papel. De esta manera, el Tribunal juzgó que un equilibrio entre ambos derechos conduce a ordenar que Ediciones El País adopte las medidas tecnológicas adecuadas (como la utilización de códigos robots.txt o instrucciones noindex, etc.) para que la página web de su hemeroteca digital en la que aparecía la información sobre las personas demandantes no pueda ser indexada por los proveedores de servicios de búsqueda en Internet. En cambio, rechazó conceder que se eliminen los nombres y apellidos de los demandantes del código fuente de la página web que contiene la noticia, ni tampoco que se adopten medidas técnicas para evitar que la noticia sea indexada por el buscador interno de la hemeroteca digital, porque ello constituiría un "sacrificio desproporcionado" de la libertad de información de la que también gozan dichas hemerotecas. En este sentido, señala la sentencia que "El llamado 'derecho al olvido digital' no puede suponer una censura retrospectiva de las informaciones correctamente publicadas en su día".

Finalmente, hemos de destacar un fallo que se refiere a ambos ámbitos de aplicación del derecho al olvido: el de una hemeroteca digital de un diario y un buscador general de internet como Google. Se trata de la sentencia de la Corte Constitucional de Colombia, de fecha 12 de mayo de 2015, que debió pronunciarse sobre la reclamación de una mujer, a la que la sentencia identifica solo con el nombre de Gloria (para evitar el efecto Streisand) que pedía que se eliminara del archivo digital del diario El Tiempo una noticia que la vinculaba al delito de trata de blancas, de la cual habían transcurrido más de diez años y, más aún, puesto que en el proceso penal había sido absuelta por haber prescrito la acción en su contra. La demandante pedía que El Tiempo fuera condenado también a que la noticia se eliminara del buscador Google. La sala de revisión del recurso de la Corte ordenó citar a Google Colombia Limitada, empresa que alegó que la gestión del buscador no era controlada por ella sino por Google Inc., con domicilio en Estados Unidos. 
Finalmente, la Corte resolvió que no correspondía la eliminación, pero sí que la noticia fuera actualizada informando el posterior sobreseimiento de la imputada y además que el diario utilice herramientas (como robots. txt o metatags) para evitar la indexación de esa noticia por motores de búsqueda, especialmente de Google. Al contrario del Tribunal Europeo, la Corte considera que hacer responsables a estos motores del contenido de las noticias que enlazan amenazaría el principio de neutralidad de internet y podría convertir a estos motores en censores de lo que aparece o no en la web (Corte Constitucional T-277/15) ${ }^{19}$.

En suma, esta sentencia razona en forma parecida al Tribunal Supremo español en cuanto a la no eliminación de la noticia y solo a la adopción de medidas que impidan la indexación por los motores generales de búsqueda y, en cambio, se muestra contraria a la decisión del Tribunal de Justicia de la Unión Europea, la que piensa no ponderó suficientemente la libertad de información tanto de Google como de los usuarios de internet y el principio de neutralidad en la red que la hace posible. En este sentido, señala la sentencia que "además de hacerle responsable por una información que aquel [Google] no generó y por la que no debe endilgársele responsabilidad, esta medida entraña la posibilidad de convertir al motor de búsqueda en un censor o controlador de los contenidos publicados por los usuarios que acceden a la red. Esto [...] puede afectar la arquitectura de Internet por la vía de desconocer sus principios rectores de acceso en condiciones de igualdad, no discriminación, y pluralismo. A su vez, se declara que una intervención de este tipo no solo tiene una mera influencia técnica en el funcionamiento de un medio de comunicación, sino que compromete, además, el derecho a la información de las personas que acceden al servicio, es decir, todos los ciudadanos" (9.8.2).

En este contexto jurisprudencial, se produce el primer fallo que reconoce el derecho al olvido en los tribunales chilenos, cuyos hechos hemos relatado al comienzo de este trabajo.

\section{La primera sentencia chilena}

El caso que narramos al comienzo, esto es, el recurso de protección presentado por una persona en contra de la empresa El Mercurio para que se eliminara de su portal de internet (emol.com) la noticia publicada hace más de diez años en que se informaba que había sido sometido a proceso por su participación en el caso Spiniak sobre una red de abusos de menores, fue fallado en contra del recurrente por la Corte de Apelaciones de Santiago por entender que la noticia era veraz y que el solo hecho de que hubieran pasado diez años no le quitaba tal carácter, dado que el recurrente no había aportado antecedentes que dieran cuenta de su actual situación procesal. De esta manera, la empresa recurrida no habría cometido acto ilícito alguno y, por el contrario, ejercía la libertad de expresión e información.

Apelada la sentencia de primera instancia, la Corte Suprema (Tercera Sala) por fallo dividido, de cuatro votos contra uno, revocó la decisión de la Corte de Apelaciones y acogió el recurso de protección (C. Sup. 21 de enero de 2016, rol No 22.243-2015). Según la sentencia, dado que no se ha cuestionado la veracidad de la noticia estamos ante lo que la doctrina ha llamado "derecho al olvido", que, según la Corte, "se refiere sustancialmente a que una persona pueda aspirar a la eliminación de una información desfavorable sobre sí misma que le provoque perjuicios actuales y que se contenga en los sistemas informáticos disponibles, y ello por una razón plausible" (cons. $3^{\circ}$ ). La sentencia entiende que en el caso este derecho, sustentado en el derecho a la vida privada y a la honra, debe primar por sobre la libertad de expresión e información teniendo en cuenta el interés público de la reinserción social de los condenados (manifestado en las leyes vigentes), el transcurso de más de 10 años desde la noticia que es el plazo máximo de prescripción contemplado en el ordenamiento, y el hecho de que la eliminación de la web no significa la desaparición de la noticia ya que se mantiene la posibilidad de encontrarla

${ }_{19}$ Acción de tutela instaurada por Gloria contra la Casa Editorial El Tiempo, disponible en http://www.corteconstitucional.gov.co/ relatoria/2015/t-277-15.htm (consulta 20 de octubre de 2016). 
mediante medios "análogos" (diario en papel).

Resuelve la Corte que "no se divisa el beneficio actual para la libertad de expresión de mantener un registro digital detectable por cualquier motor de búsqueda informático, de una noticia que de todos modos puede ser consultada por métodos análogos mediante el ejercicio investigativo profesional de quien esté interesado en ello. De lo que se trata no es que la noticia deje de existir, sino de no brindar accesos automáticos y facilitadores que hagan más difícil o imposible la recuperación y reinserción social del individuo y de su familia, caso este último que no debería afectarse jamás.- El lapso de más de diez años transcurridos desde la fecha de la noticia -período suficiente para la prescripción penal de la mayoría de los delitos más graves- resulta más que suficiente para resolver provisoriamente y en cautela de las garantías constitucionales antes mencionadas, que debe procurarse el 'olvido' informático de los registros de dicha noticia" (cons. $5^{\circ}$ ). En la parte resolutiva, la sentencia se limita a ordenar a la empresa periodística la eliminación sólo del registro informático de la noticia dentro del plazo de tres días.

La decisión no fue compartida por la Ministra María Eugenia Sandoval, que redactó un fundamentado voto disidente, en el que alude a la sentencia del Tribunal de Justicia Europeo y a la de la Corte Constitucional de Colombia. La Ministra señala que no parece que en este caso pueda primar el derecho al olvido sobre el interés público y la libertad de informar, primero por la naturaleza del delito (abuso sexual de menores), de fuerte connotación social y, en segundo lugar, porque el plazo de diez años debe ser relativizado, ya que el interesado fue condenado por dicho delito sólo el 2011, y terminó de cumplir la pena el 2013. De esta manera, concluye: "no es procedente otorgar la cautela a las garantías constitucionales solicitadas por el recurrente de protección, con base en el fundamento esgrimido en el recurso planteado, de aplicar en la especie el derecho al olvido, por cuanto, en el evento de considerarse éste procedente en un delito de abusos sexuales, el tiempo transcurrido no justifica la aplicación del mismo" (cons. $16^{\circ}$ del voto disidente).

En coincidencia con los planteamientos disidentes se ha criticado la sentencia por desdeñar el desarrollo posterior de la noticia que demuestra que el transcurso del tiempo era muchísimo menor (el plazo debería haberse contado desde que el afectado terminó de cumplir la condena en 2013), y también por no tomar en cuenta que no se trataba de un proceso penal cualquiera, sino de uno de alta connotación pública (caso Spiniak). Se agrega que la Corte nunca individualiza cuál fue el acto ilegal o arbitrario cometido por la recurrida ni tampoco razona en qué forma se produjo la lesión de los derechos a la integridad psíquica, honra o vida privada ${ }^{20}$.

Coincidimos con estas opiniones críticas al voto de mayoría, como ya lo adelantamos en una opinión vertida en la columna del mismo Diario El Mercurio, titulada "Olvidarte: ¿nunca?", de fecha 11 de febrero de 2016 (Corral, 2016).

No obstante, debe consignarse que tanto los jueces de la mayoría como la disidente estuvieron de acuerdo en que sí existe un "derecho al olvido" en internet y sólo discreparon en si dicho derecho era aplicable o no al caso. En ese sentido puede hablarse de un precedente jurisprudencial en el ordenamiento jurídico chileno ${ }^{21}$ que exige profundizar en cómo debería configurarse dicho derecho en nuestro sistema jurídico, tomando en cuenta los desarrollos que esta facultad ha tenido en jurisdicciones extranjeras o internacionales. A ello están encaminadas las reflexiones que siguen.

\footnotetext{
20 Son críticas de Anguita (2016), pp. 106-109.

${ }^{21}$ Se menciona como un antecedente de recepción del derecho al olvido la sentencia de Corte de Apelaciones de Valparaíso de 30 de julio de 2012, Rol № 228-2012 (Cámara de Diputados, 2016, 60). Pero en realidad en este caso no se trató del ejercicio del derecho al olvido sino de un recurso de protección por la publicación en páginas web de expresiones que afectaban la honra del recurrente, y que él pedía eliminar. Un análisis del caso puede verse en Anguita (2016), pp. 180-185. Con posterioridad a la sentencia de la C. Sup. de 21 de enero de 2016, la Corte de Antofagasta rechazó un recurso de protección presentado por una persona que fue despedida de su trabajo al constatar el empleador que el año 2004 había sido condenada por robo con intimidación por la mantención en las webs de dos medios periodísticos de la noticia, pese a haber aclarado ya sus antecedentes penales. No obstante, ni el recurrente ni los medios recurridos ni tampoco la Corte hacen alusión al derecho al olvido, que claramente era lo que se discutía. El fallo rechaza el recurso por entender que la libertad de expresión debe primar por sobre el honor al tratarse de la comisión de un delito que es considerado como de interés público por la ley No 19.773 (art. 30). Cfr. C. Antofagasta 7 de diciembre de 2016, rol № 3707-2016. La sentencia no fue revisada por la Corte Suprema, ya que no fue objeto de recurso de apelación.
} 


\section{Intento de configuración jurídica del derecho al olvido en internet}

5.1. ¿Derecho o criterio para resolver conflictos de derechos fundamentales?

Una primera cuestión que convendría despejar es si la categoría de "derecho al olvido" es realmente un nuevo derecho que goza de una autonomía o perfilamiento propio, o si no estamos más bien ante un criterio que nos permite resolver algunos de los conflictos que se plantean entre los derechos fundamentales a la libre expresión, por una parte, y a la vida privada, por otra.

En este sentido, se ha planteado que

El derecho al olvido puede y debe ser analizado desde a la lógica de los derechos fundamentales, y más concretamente, desde la lógica de los conflictos de derechos, que adopta esta forma didáctica para justificar cierto reforzamiento de la privacidad y de otros derechos, o lo que es lo mismo, establecer límites a la libertad de expresión. (Leturia, 2016, p. 97)

Se agrega que incluso aunque la categoría venga a ser reconocida por el ordenamiento jurídico, ello debería entenderse como un ejercicio de ponderación, realizado por el legislador para brindar mayor certeza jurídica y así facilitar el trabajo judicial (Leturia, 2016). El mismo autor señala que

Los problemas jurídicos asociados al olvido y la memoria pública de hechos del pasado pueden abordarse perfectamente como problemas de conflicto de derechos fundamentales, y más concretamente, como situaciones que justifican limitaciones legítimas al ejercicio de la libertad de expresión e información (Leturia, 2016, p. 108).

Pero, aun consintiendo en que el derecho al olvido pueda ser utilizado como criterio para determinar los límites de la libertad de expresión, ello no quiere decir que no pueda ser considerado como una facultad para exigir de otra persona una determinada conducta, que es la estructura básica de todo derecho. Por lo demás, el derecho a la vida privada y el derecho al honor también pueden ser considerados criterios para limitar la libertad de expresión, y no se puede negar que ya cuentan con una fisonomía jurídica propia como derechos.

Por cierto, siendo un derecho de la personalidad produce el deber general de respeto por parte de terceros $y$, concretamente, a realizar a las acciones tendientes a procurar la desaparición o bloqueo de la noticia que permite que el hecho siga estando presente en la esfera pública, esto último a petición privada del afectado o ante sentencia judicial dictada a requerimiento de aquel22.

\section{2. ¿Derecho autónomo o derivado?}

Una vez que convenimos en que estamos ante un derecho, debemos preguntarnos si se trata de un derecho autónomo, con sus propios perfiles o características, o más bien de una nueva manifestación o expresión de un derecho ya reconocido, del cual sería una facultad derivada.

La falta de reconocimiento normativo ha llevado a la jurisprudencia a buscar el sustento de la pretensión del que pide que se eliminen noticias de su pasado en derechos ya establecidos. El más aludido es el derecho al respeto y protección de la vida privada. El derecho al olvido no sería más que una nueva expresión de las múltiples que ha generado la custodia legal de los espacios de reserva o intimidad de las personas naturales ${ }^{23}$. En otras ocasiones, se le conecta también con el derecho a la honra, ya que normalmente las noticias o datos que se busca eliminar lesionan la reputación o fama de la persona.

Cuando el derecho al olvido se reclama en el ámbito del procesamiento de datos personales, aparece la idea de que se trataría de una facultad más bien ligada al llamado derecho a la autonomía informativa, entendido

\footnotetext{
${ }^{22}$ Aunque algunos ya han planteado la posibilidad de establecer la eliminación automática, y sin conocimiento del titular, de cierta información digital después de un determinado plazo: cfr. De Terwangne (2012), p. 61.

${ }^{23}$ En el ámbito estadounidense es usual relacionar el "rigth to be forgotten" al "right to privacy": cfr. Cook (2015), $122-124$.
} 
como el poder de control que se reconoce a la persona sobre los datos informativos que pueden circular en la sociedad respecto de ella (Muñoz, 2015).

Hay quienes se muestran críticos de derivar el derecho al olvido del derecho a la honra o a la vida privada, ya que las personas pueden exigir que se eliminen noticias que no lesionan la honra y que tampoco pertenecen a la vida privada. Se aduce, por ejemplo, los casos de eliminación de noticias que dan cuenta de una investigación o una condena penal, que no forman parte del ámbito de reserva protegido por la intimidad $y$, sin embargo, se reconoce el derecho al olvido cuando la noticia ha perdido vigencia o interés. Por ello, se propone derivar el derecho al olvido del llamado derecho al libre desarrollo de la personalidad ya que con la constante presencia de esas informaciones caducas el individuo vería perturbada la posibilidad de desarrollar su vida como legítimamente quisiera ${ }^{24}$.

No faltan quienes derivan el derecho al olvido de una mezcla de todos estos derechos: autonomía informativa, vida privada, honor y libre desarrollo de la personalidad, al que puede agregarse, como hace la sentencia chilena, la integridad psíquica y la dignidad humana (Martínez, 2015).

5.3. Nuestra posición: un derecho en formación a partir del derecho a la vida privada

A nuestro entender el derecho al olvido está en proceso de configuración como un derecho de la personalidad. Como es sabido, la protección de bienes extrapatrimoniales de la persona se inició en la doctrina alemana por medio del llamado Derecho General de la Personalidad que se planteaba como un único derecho que podía adaptarse para hacer frente a las diversas agresiones que podía sufrir el individuo humano en el ámbito no patrimonial25. Posteriormente, la doctrina y la jurisprudencia han ido reconociendo una pluralidad de derechos que tienen por objeto proteger la personalidad, y se han ido dando nombres específicos a cada uno de ellos: derecho a la vida, derecho a la integridad corporal, derecho a la intimidad, derecho al honor, derecho a la libre expresión, etc. Estos derechos se han ido delimitando y ajustando con la experiencia de las diferentes modalidades de atentados o lesiones que puede sufrir la persona en el medio en el que vive. No es raro, en consecuencia, que muchos de ellos vayan conformándose en forma progresiva y que puedan encontrarse algunos que todavía no han recibido una consagración completa y generalizada. En su minuto sucedió con el derecho a la intimidad, y hoy se encuentran en esa fase el derecho a la imagen, el derecho a la identidad, el derecho a la integridad genética, etc. El mismo derecho a la autonomía informativa se encuentra aún en esta fase de desarrollo.

En una etapa más incipiente está el derecho al olvido, cuya consistencia, perfiles, limitaciones y ámbitos de aplicación se encuentran sujetos a discusión. Pero ya se advierten indicios de su surgimiento e incluso formalización en normas internas o internacionales. En ese sentido, es muy indicativo que el Reglamento 2016/679 de la Unión Europea protección de las personas físicas en lo que respecta al tratamiento de datos personales, haya insertado en el título del art. 17, después de "derecho de supresión", la expresión "derecho al olvido", si bien entre paréntesis ${ }^{26}$.

En cualquier caso, si se estima que el derecho al olvido aún no ha adquirido la suficiente independencia, pensamos que bien puede considerársele una expresión del derecho al respeto a la vida privada.

No parece, en cambio, que esté basado en el derecho a la honra, porque no necesariamente se requerirá que haya un menoscabo a la fama o reputación de la persona, bastando que haya una intromisión en aspectos propios de la reserva de privacidad. Desechamos también que sea una expresión del derecho al libre desarrollo de la personalidad, porque la misma formulación de este derecho es tan vaga e imprecisa que puede ser funcional para explicar cualquier derecho, de modo que en realidad no explica ninguno ${ }^{27}$.

\footnotetext{
${ }^{24}$ Esta parece ser la opinión de Anguita (2016), pp. 34-35, quien hace ver que el Tribunal Constitucional chileno ha declarado que el derecho al desarrollo libre de la personalidad puede considerarse una expresión de la dignidad de toda persona que expresamente consagra nuestra Carta Fundamental (STC 13 de enero de 2011, rol № 1683-2010, cons. 50).

${ }^{25}$ Cfr. Larenz (1978), pp. 160-165.

${ }^{27}$ La misma sentencia del Tribunal Constitucional que se invoca como apoyo a la existencia de este derecho en nuestra Carta Fundamental aclara que de ello "no puede colegirse que el libre desarrollo de la personalidad constituya fundamento legítimo para atropellar los derechos de otros seres humanos igualmente dignos" (STC 4 de enero de 2011, rol № 1683-2010, cons. 51\%).
} 
La autonomía informativa parece estar todavía muy vinculada al procesamiento de datos, de modo que no serviría para fundamentar el derecho al olvido que puede ejercerse fuera de ese ámbito.

Los argumentos en contra del derecho a la vida privada provienen de que el derecho al olvido puede recaer no sobre informaciones relativas a la intimidad personal sino también sobre hechos que son públicos, como una condena penal o una información, en el sentido amplio de la palabra, cuya difusión pública fue consentida o incluso promocionada en su día por el que ahora se siente afectado.

Nos parece que estas observaciones no justifican que se separe el derecho al olvido del derecho al respeto a la vida privada. En realidad, tanto en la condena penal como en las informaciones consentidas, los hechos en sí son privados, pero el interés público o el consentimiento hacen que su difusión pública sea legítima. Una vez que, por el paso del tiempo, ese interés público decaiga o desaparezca, o que el consentimiento pueda ser retractado sin lesionar los derechos de terceros, los hechos volverán a su natural carácter de privados, y siendo así podrán ser objeto del derecho al olvido, como expresión del derecho a la protección de la vida privada.

\subsection{Discusión sobre la denominación}

Se ha hecho ver que el nombre del nuevo "derecho al olvido" es incorrecto, ya que indudablemente toda persona tiene derecho, como parte de la libertad de expresión, a no recordar algún hecho y nadie podría forzarla a relatar hechos que ella quiere olvidar. En realidad, el derecho al olvido es más bien un derecho a favorecer el olvido por parte de terceros de ciertos hechos del pasado de alguien. En este sentido, es más apropiada la expresión que se usa en los escritos jurídicos anglosajones: "the right to be forgotten": el derecho a ser olvidado, pero en un sentido de limitar el derecho a la información por parte de terceros haciendo desaparecer la noticia o restringiendo el acceso a ella ${ }^{28}$.

Con todo, pareciera que la expresión "derecho al olvido” está ya asumida por el gran público, por los medios e incluso por la jurisprudencia y la doctrina jurídica, de modo que no parece viable pretender modificarla por otra, aunque pueda esta ser más adecuada. Lo importante es que se aclare que cuando usamos esta denominación no estamos hablando del derecho a no referirse a episodios del pasado, ni tampoco a forzar que los demás realmente olviden dichos acontecimientos. Se trata de evitar que los registros de esos hechos en la prensa, bases de datos o plataformas de internet puedan ser difundidos nuevamente o puedan ser consultados por cualquier persona sin ninguna restricción.

\subsection{Modalidades de aplicación}

Más arriba hemos identificado tres etapas en la evolución del llamado derecho al olvido. Ahora debe considerarse que esa evolución ha sido acumulativa, es decir, el paso de una a otra no deja sin aplicación a la primera, sino que ambas se mantienen vigentes. Por ello, podemos decir que las tres etapas pueden ser aplicadas en la actualidad y así se convierten en modalidades de ejercicio o de aplicación del derecho al olvido.

Una primera modalidad del derecho al olvido es aquella en la que puede ser invocado para evitar que los medios de prensa vuelvan a referirse o a dar cuenta de hechos públicos de la vida pasada de una persona. Se trata de una prohibición de "re-publicación".

La segunda modalidad es la que se refiere a la eliminación o bloqueo de datos relativos a una persona que se encuentran en una base o banco de datos, los que se consideran obsoletos o caducos. Este derecho al olvido podría denominarse derecho al olvido informático, puesto que hoy prácticamente todas las bases de datos se mantienen y manejan por medio de equipos informáticos o computadores.

Finalmente, tenemos la modalidad de pedir el retiro de contenidos de plataformas de internet, que podría revestir a su vez dos formas: el derecho a que la fuente (página web, blog, redes sociales) donde aparece la noticia la retire o elimine, y el derecho a que los motores de búsqueda particulares o generales no enlacen las fuentes donde aparece la noticia de modo que ella no

${ }^{28}$ En sentido crítico, advierte esta diferencia, De Beats (2016), p. 58. 
sea arrojada como resultado de una consulta. En ambos casos, podríamos hablar de derecho al olvido digital, ya que el Diccionario de la Real Academia de la Lengua contempla como una de las acepciones de "digital" la de referirse a medios de comunicación que "se publican en internet".
Nos interesa profundizar específicamente sobre el derecho al olvido digital, que normalmente implicará las dos formas de aplicación: de la fuente directa y de los buscadores.

\section{Una caracterización aproximativa al derecho al olvido digital}

\subsection{Aspectos comunes y específicos}

Como una versión del derecho al olvido, el derecho al olvido digital comparte con el primero varios aspectos, como el que se trata de un derecho cuya titularidad corresponde a personas naturales, y no jurídicas, y que estamos ante un derecho en proceso de formación, que va tomando progresiva autonomía de su matriz que es el derecho al respeto a la vida privada. Además, puede señalarse que, al igual que todo derecho al olvido, el derecho al olvido digital se ejerce contra informaciones que se admiten como veraces y legítimamente publicadas en su momento, ya sea por el interés público comprometido o por el mismo consentimiento del interesado. Igualmente, las informaciones deben ser contrarias a la intimidad actual del titular, si bien muchas veces además serán contrarias a la honra, pero esto último no es indispensable. Adicionalmente las noticias impugnadas ya no presentan el interés público que en su día justificó su publicación, de modo que en la actualidad se observan como obsoletas, excesivas, irrelevantes o inconducentes, y en este desaparecimiento del interés público tiene incidencia el paso del tiempo, dependiendo la extensión del plazo del peso relativo de dicho interés ${ }^{29}$. Finalmente, para demandar la eliminación de la noticia no es necesario acreditar que su libre acceso causa perjuicios al titular. Esto sólo será necesario si se pretende hacer valer la responsabilidad civil por violación del derecho al respeto de la vida privada.

El derecho al olvido digital tiene, sin embargo, algunas características que le son propias, a saber: a) El objeto del derecho no es impedir una nueva publicación que traiga al presente hechos del pasado, sino eliminar la misma publicación pasada que no obstante el tiempo transcurrido sigue siendo pública y fácilmente accesible en el ámbito de internet.

b) La reclamación del afectado puede dirigirse contra la fuente de internet que contiene la noticia o contra los buscadores que intermedian entre quienes buscan información y las diversas plataformas de internet que la contienen.

c) Al tratarse de buscadores - normalmente empresas que tienen intereses económicos - el interés público que justifica la conservación de la noticia puede basarse, al menos en línea de principio, en la libertad de expresión e información y en la libertad de empresa o de libre iniciativa en materias económicas.

d) La eliminación de los antecedentes de internet puede ser menos lesiva para el interés histórico o periodístico si ellos tienen una fuente en papel (caso de los diarios con hemerotecas digitales).

\subsection{Legitimados activos y pasivos}

La legitimación activa para ejercer este derecho la tendrá la persona que vea lesionada su intimidad por la mantención de la noticia en internet y por su libre acceso a través de buscadores digitales. Si se trata de un menor de edad o de alguna persona que esté incapacitada, en su interés podrán actuar en su nombre sus representantes legales ${ }^{30}$.

\footnotetext{
${ }^{29}$ Un criterio que puede considerarse es el plazo establecido para la eliminación de antecedentes penales, si se trata de noticias referidas a la comisión de delitos, el que en todo caso deberá contarse desde el término de cumplimiento de la condena.

${ }^{30}$ La posibilidad de que los herederos puedan ejercer el derecho para proteger una especie de privacidad póstuma del difunto, es discutida por De Baets (2016), pp. 63-64.
} 
Como ya anotábamos, en cuanto a los legitimados pasivos existen dos grandes posibilidades: la fuente de la noticia digital y las empresas que gestionan motores de búsqueda particulares o generales en internet.

La cuestión no es fácil de resolver. Por un lado, se puede decir, como la Corte Constitucional colombiana, que los motores de búsqueda tipo Google no son responsables del contenido de las noticias, sino meros intermediarios, de modo que el derecho al olvido debiera ejercerse contra el titular de la web o URL que aloja la noticia en su servidor. Esta posición tiene la ventaja de que, suprimida la noticia en su fuente, ya no podrá aparecer en ningún motor de búsqueda de internet. Pero esta posición tiene también inconvenientes serios, ya que la libertad de información se ve mucho más radicalmente afectada: si el medio digital no tiene respaldo en papel, la noticia desaparecerá para siempre. Además, si la noticia se ha difuminado por muchas páginas web, blogs o Facebook no hay manera práctica de ejercer judicial o administrativamente el derecho, siendo más factible y útil obtener que no sea enlazada por los motores de búsqueda.

Por esto, parece menos lesiva y más eficaz la legitimación pasiva preferente, si bien no exclusiva, de los motores de búsqueda. Puede tratarse de motores de búsqueda particulares como los que presentan determinados sitios web para buscar dentro de sus contenidos (hemerotecas de periódicos digitales) o también motores de búsqueda generales como Google y sus similares. También la acción derivada del derecho al olvido podría ejercerse en contra de la fuente directa, pero para pedir, no la eliminación de la noticia en su plataforma (página web, blog, red social), pero sí la adopción de medidas tecnológicas que impidan que los buscadores particulares o generales puedan indexarlas para arrojarlas como resultado de una consulta.
Respecto de Google se presenta la cuestión suscitada en España y Francia sobre si basta la eliminación del enlace en el buscador local, o debe realizarse sobre todo el ámbito geográfico abarcado por la empresa (derecho al olvido global o universal). En principio, pareciera bastar la eliminación del enlace en el buscador local sin que sea necesario que la noticia sea eliminada en todo el orbe.

También se produce el problema de si hay que emplazar a la matriz de Google con domicilio en Estados Unidos, o a la empresa local que, aunque sin gestionar el motor de búsqueda, mantiene la marca y administra la publicidad. Como hemos sostenido que el derecho al olvido digital no tiene por qué basarse únicamente en la normativa propia de la gestión de datos personales, nos parece que no cabe aquí excluir la legitimación pasiva de la empresa local con el argumento de que ella no es la que puede considerarse responsable del control de los datos. Basta que tenga una representación oficiosa de la empresa matriz para que pueda ser emplazada en su nombre.

\subsection{Limitaciones}

Las excepciones al derecho al olvido provienen de una preferencia por la libertad de informar determinada por la existencia de un interés público que legitima la intromisión en la vida privada. En este sentido, el derecho al olvido resulta derrotado por lo que podríamos denominar un derecho a la memoria, que puede considerarse una forma de ejercicio del derecho a la libertad de emitir opinión e informar, así como de la libertad para acceder a la información y utilizarla para fines legítimos ${ }^{31}$.

El interés público no es el que autorizó en su día la publicación, sino que debe existir al momento en que se pide la eliminación de la nota por haber cumplido ya su finalidad informativa. Puede ser el mismo interés o puede ser otro diverso.

\footnotetext{
${ }_{31}$ Esta libertad se puede asociar con la libertad de empresa que en nuestro sistema constitucional aparece restringida a la libre iniciativa en materia económica (art. 19 № 21 Const.), pero que debería entenderse ampliada a fines no lucrativos como los que persiguen las personas jurídicas de derecho privado sin fines de lucro. La discusión en este campo ha sido si una empresa con fines económicos, como un buscador de internet, puede alegar en contra del derecho al olvido la libertad de informar en beneficio de los que navegan en la red. En el caso "Costeja" el Abogado General entendió que Google podía alegar tanto la libertad para conducir sus negocios como la de informar: Jääskinen (2013), $n^{\circ}$ 132. En España se ha sostenido que como el derecho a la libre empresa está recogido en la parte programática de la Constitución (art. 38) debería ceder en caso de enfrentarse a un derecho fundamental como sería el derecho a la intimidad, pero que ello no sucedería tan fácilmente si la empresa, como un buscador de internet, puede alegar igualmente otro derecho fundamental como la libertad de expresión e información: cfr. Martínez (2015), pp. 110-111; 126-127. En la Constitución chilena el derecho a la libre iniciativa económica está en el mismo nivel normativo que el derecho a la vida privada, por lo que no cabría considerarlo derrotable en cualquier caso cuando colisione con este último. En todo caso, la cuestión puede ser más teórica que práctica dado que normalmente este tipo de medios digitales podrán aducir tanto la libertad de empresa como la libertad de expresión e información.
} 
En aplicación de este criterio general, pueden definirse varios supuestos en los que el derecho al olvido digital no debiera prevalecer:

a) Cuando el solicitante sea una autoridad pública o intenta llegar a serlo (candidatos a cargos electivos).

b) Cuando se trata de delitos que no son susceptibles de amnistía ni de prescripción, como los crímenes de lesa humanidad ${ }^{32}$.

c) Cuando se trata de delitos cuyos autores pueden representar un peligro para ciertos ambientes, por los que la ley exige tener acceso a la información de sus condenas ${ }^{33}$.

d) Cuando un determinado hecho tiene relevancia para mantener la memoria histórica de la comunidad ${ }^{34}$.

\subsection{Aplicación modulada por principio de ponderación (mínima intervención)}

En los casos en los que debe prevalecer el derecho al olvido digital, su aplicación debiera ser gradual según los diversos casos, de modo que se lesione lo menos posible las libertades de emitir opinión e informar y la de acceder a la información y utilizarla con fines legítimos. Se aplicará el principio de ponderación en su aspecto de mínima intervención ${ }^{35}$.

\section{Podríamos sugerir los siguientes criterios:}

$\left.1^{\circ}\right)$ La solicitud debería hacerse valer contra los motores de búsqueda y no frente a las fuentes originarias. En principio, bastará con los motores locales, y solo cuando fundadamente la eliminación local no es suficiente para resguardar la honra o vida privada de la persona procederá una eliminación geográfica más amplia, hasta llegar a la global o universal.

$2^{\circ}$ ) Si se requiere a la fuente original, deberá primero preferirse una actualización de la información sin que se ella sea eliminada (por ejemplo, en casos de absolución en procesos penales). Así lo propone el dictamen № 203, de 12 de agosto de 2016, del Consejo de Ética de los Medios de Comunicación Social:

... aunque las decisiones editoriales corresponden a cada medio, el Consejo no considera conveniente la eliminación de información cuando ella implique un perjuicio a la libertad de prensa y al derecho a la información ciudadana. Sin embargo, hay otras formas de actualizar la información, tal como la inclusión de mensajes de advertencia que lo informado debe complementarse con hechos ocurridos con posterioridad (por ejemplo, que den cuenta de la existencia de una sentencia que absuelva a una persona acusada de un delito). Otra práctica recomendable consiste en agregar comentarios aclaratorios de errores incurridos al momento de la publicación y detectados de forma tardía. (Consejo de Ética de los Medios de Comunicación Social, 2016).

$3^{\circ}$ ) En caso de que esto no sea bastante, se puede ordenar la aplicación de herramientas tecnológicas que impidan que ese enlace sea accesible a través de motores de búsqueda externos.

$\left.4^{\circ}\right)$ Supletoriamente, se podrá requerir que la noticia no sea accesible por el motor de búsqueda interno del medio.

$5^{\circ}$ ) Solo en casos muy excepcionales, y en que todas las medidas anteriores se revelen ineficaces, podrá pedirse que se borre la información digital, pero siempre que de ella quede constancia en un soporte material, como papel, celulosa de película, microfilms.

De esta manera, pensamos que en el caso chileno la posición correcta habría sido el rechazo por varias razones: primero, porque el delito al que se refería la noticia es de aquellos que la misma ley ordena mantener accesibles por cualquier persona mediante un registro

\footnotetext{
32 En este sentido se pronuncia la Corte Constitucional colombiana.

${ }^{33}$ Por ejemplo, los atentados sexuales contra niños. En Chile, la ley № 20.594, de 2012, creó un Registro de personas inhabilitadas para ejercer funciones en ámbitos educacionales o con menores de edad, y estableció la obligación de toda institución que desee contratar a una persona para una función o empleo que implique relación directa con menores de edad de consultar dicho registro. No hay normas que limiten la conservación de esta información por el paso del tiempo (cfr. art. 6 bis, Decreto Ley № 645, de 1925, sobre el Registro general de las condenas). Esta duración permanente del registro puede transformarse en una pena perpetua que imposibilite la reinserción social de estas personas y su rehabilitación.

${ }^{34}$ Una crítica de la aplicación del derecho al olvido para los desarrollos de la historia, especialmente de aquella basada en la vida privada de las personas, puede verse en De Baets (2016), p. 57 ss.

${ }^{35}$ La jurisprudencia del Tribunal Constitucional alemán ha señalado que para aplicar el principio de proporcionalidad, entre otros requisitos, implica que entre varias alternativas de intervención sobre un derecho ha de preferirse la que lo afecte menos (mínima intervención). Cfr. Rainer Martínez \& Zúñiga (2012), p. 71.
} 
especial; segundo, porque el tiempo transcurrido no era suficiente para que la noticia deviniese obsoleta, dada la condena y su cumplimiento, y; tercero, porque se refería a una autoridad pública (oficial de carabineros). Por último, si se hubiera llegado a la conclusión de que procedía el derecho al olvido, debería haberse dispuesto una medida de menor afectación del derecho a la información, como la utilización de dispositivos tecnológicos que impidieran el enlace de la noticia en los motores de búsqueda de internet, como Google.

\subsection{Aplicabilidad de la normativa sobre protección de} datos

Como hemos visto, cuando aparecen los problemas planteados en el derecho al olvido en internet, principalmente con los motores de búsqueda y las hemerotecas digitales, ante la falta de una regulación normativa específica, las autoridades han recurrido a la aplicación de las leyes dictadas para la protección de los datos personales en los sistemas de procesamiento de datos. Esta tendencia fue la que reconoció el Tribunal de Justicia de la Unión Europea en el "caso Costeja", al interpretar la directiva europea de protección de datos y señalar que en ese marco el motor de búsqueda de Google podía considerarse un responsable de procesamiento de datos. Pero nos parece que el Tribunal en esta parte forzó la interpretación de la directiva que, claramente, no estaba pensada para el tipo de operación que realizan los motores de búsqueda. Como señala en su informe el Abogado General, en cuanto un motor de búsqueda sólo recopila información de terceras fuentes con el único objeto de poder exhibirlas como resultados de consultas temáticas, no puede considerarse un controlador responsable de datos personales.

El informe señala, entre otras razones, para descartar la aplicación del concepto de responsable del procesamiento de datos a Google, que

el proveedor de servicios de motor de búsqueda en internet no tiene relación con el contenido de los terceros fuentes como las páginas web, en las que pueden aparecer datos personales. Por otra parte, como el motor de búsqueda funciona sobre la base de las copias de las páginas web que su rastreador ha recuperado y copiado, el proveedor del servicio no tiene ningún medio para cambiar la información de los servidores host. La provisión de localizadores de información no implica ningún control sobre el contenido (Jääskinen, $\left.n^{\circ} 86\right)$.

No vemos que esta situación vaya a variar por la entrada en vigencia del Reglamento sobre protección de datos personales, ya que la definición de "responsable del tratamiento" (de datos) permanece prácticamente igual (art. $\left.7 \mathrm{~N}^{\circ} 4\right)^{36}$.

De esta manera, solo por vía analógica y en espera de una legislación que se haga cargo de los problemas derivados de internet en esta materia, pueden considerarse aplicables las regulaciones legales dictadas para la protección de los derechos de las personas en sistemas de tratamiento de datos. Pero no hay que olvidar que estamos ante una modalidad diversa de ejercicio del derecho al olvido que en ocasiones exigirá ocupar criterios distintos que aquellos que son adecuados para la eliminación o supresión de datos personales ${ }^{37}$.

\section{Perspectivas de futuro}

No se ven indicios de que en nuestro país tengamos pronto un reconocimiento normativo del derecho al olvido digital. Este propósito ha sido invocado por un proyecto de ley presentado el 7 de abril de 2016 por una moción de los diputados Guillermo Ceroni y Gabriel Farcas (Boletín $\left.N^{\circ} 10608-07\right)$, pero no parece que tenga posibilidades de ser aprobado ya que no cuenta con el patrocinio del Poder Ejecutivo. Además, el texto presenta limitaciones importantes que aconsejan que no se le considere. Por de pronto se restringe al ámbito del procesamiento de datos personales, ya que se circunscribe a una reforma a la ley $N^{\circ} 19.628$ y, aunque define el derecho al olvido

\footnotetext{
36 Por ello el reconocimiento del derecho al olvido como derecho a la supresión de datos (art. 17) debería tener, a nuestro juicio, un ámbito más reducido que el que parece a primera vista.

${ }^{37}$ Con razón se ha propuesto distinguir entre el derecho al olvido (rigth to be forgotten) y el derecho a borrar datos (the right to erasure): cfr. Ambrose \& Ausloos (2013), pp. 14-16.
} 
de un modo amplísimo - como "la facultad irrenunciable que tiene el titular de uno o más datos personales para exigir la cancelación o la disociación de datos relativos a su persona, cuando su publicación o exposición carezca de fundamento legal, cuando se trate de un dato caduco, o bien afecte el libre desarrollo de alguno de sus derechos fundamentales" -, señala que quedan excluidos los bancos de datos gestionados por organismos públicos y además los medios de comunicación social a los que se aplica la ley $N^{\circ} 19.733$, sobre Ejercicio del Periodismo y Libertad de Prensa, la que no señala nada sobre el derecho al olvido. Esto podría implicar la inutilidad de la consagración del derecho que se pretende, ya que la ley $N^{\circ} 19.733$ contiene un concepto de medio de comunicación social tan amplio, que pueden incluirse las páginas web, los blogs, los motores de búsqueda y otros mecanismos de expresión utilizados en internet.

Por su parte, el Informe de Evaluación de la Ley $N^{\circ}$ 19.628 elaborado por la Cámara de Diputados, si bien se refiere extensamente al "derecho al olvido" (Cámara de Diputados, 2016), curiosamente en sus conclusiones no propone ninguna modificación que tienda a su reconocimiento (Cámara de Diputados, 2016). En realidad, pareciera que el actual derecho a la eliminación de los datos de la referida ley puede ser suficiente en este ámbito para la aplicación criteriosa del derecho al olvido, aunque ella no puede ser aplicada, sino analógicamente y con adecuaciones, al derecho al olvido en el ámbito de internet o derecho al olvido digital.

Respecto de este último, pensamos que es preferible que su reconocimiento, así como sus limitaciones y formas de aplicación, se vayan construyendo por la vía jurisprudencial, sobre la base de criterios que vayan surgiendo de la doctrina y de las experiencias del derecho extranjero. La acción de protección en resguardo del derecho al respeto de la vida privada de la persona y la familia consagrado expresamente en nuestra Constitución (arts. $19 \mathrm{~N}^{\circ}$ 4), puede ser idónea para marcar una ruta que permita una cristalización más definitiva de este derecho y de su confrontación con las libertades de expresión y de empresa. Ese material acumulado, con aciertos y errores, servirá de buen cimiento para construir una regulación legal que presente características de perdurabilidad por la sensatez y ponderación de sus determinaciones.

\section{Referencias}

Ambrose, M. L. \& Ausloos, J (2013). The Right to Be Forgotten Across the Pond. Journal of Information Policy 3, 1-23.

Ambrose, M. L. \& Ausloos, J. (2013). The right to be forgotten across the pond. Journal of Information Policy, 3, 1-23.

Anguita Ramírez, P. (2007). La protección de datos personales y el derecho a la vida privada. Régimen jurídico, jurisprudencia y Derecho comparado. Santiago: Editorial Jurídica de Chile.

Anguita Ramírez, P. (2016). Acciones de protección contra Google. Análisis del llamado derecho al olvido en buscadores, redes sociales y medios de comunicación. Santiago: Librotecnia.

Cámara de Diputados (2016), Evaluación de la ley No 19.628, Protección de la vida privada, disponible en http:// www.evaluaciondelaley.cl/ley-n-19-628-sobre-proteccion-de-la-vida-privada/foro_ciudadano/2015-12-28/124429. html (consulta 19 de octubre de 2016).

Consejo de Ética de los Medios de Comunicación Social (2016), Dictamen № 203, sobre contenidos digitales en los medios y el denominado "derecho al olvido", disponible en http://www.consejodeetica.cl/medios_australes/fallos/ Resolucion203.pdf (consulta 29 de diciembre de 2016) Ambrose, M. L. \& Ausloos, J. (2013). The right to be forgotten across the pond. Journal of Information Policy, 3, 1-23.

Cook, L. (2015). The right to be forgotten: a step in the right direction for Cyberspace Law and Policy. Journal of Law, Technology \& the Internet, 6, 121-132. 


\section{Hernán Corral Talciani}

Corral Talciani, H. (2016). "Olvidarte: ¿nunca?", en El Mercurio 11 de febrero de 2016, disponible en http://www. elmercurio.com/blogs/2016/02/11/39298/Olvidarte-nunca.aspx (consulta 15 de octubre de 2016).

De Baets, A. (2016). A historian's view on the right to be forgotten, International Review of Law, Computers \& Technology, 30:1-2, 57-66.

De Terwangne, Cécile (2012). Privacidad en Internet y el derecho a ser olvidado/derecho al olvido. Revista de Internet, Derecho y Política 13, pp. 53-66.

Jääskinen, N. (2013). Opinion of Advocate General caso C-131/12, 25 de junio, disponible en http://curia.europa.eu/juris/document/document_print.jsf?doclang=EN\&text=\&pagelndex=0\&part=1\&mode=Ist\&d ocid=138782\&occ=first\&dir=\&cid=45442 (consulta 10 de octubre de 2016).

Larenz, K. (1978). Derecho Civil. Parte general. Madrid: Editorial Revista de Derecho Privado (trad. M. Izquierdo).

Leturia, F. J. (2016). Fundamentos jurídicos del derecho al olvido. ¿Un nuevo derecho de origen europeo o una respuesta típica ante colisiones entre ciertos Derechos fundamentales? Revista chilena de Derecho, 43, 1, 91-113.

Martínez Otero, J. M. (2015). El derecho al olvido en Internet: debates cerrados y cuestiones abiertas tras la STJUE Google vs AEPD y Mario Costeja. Revista de Derecho Político 93, 103-142.

Muñoz Massouh, A. M. (2015). Eliminación de datos personales en internet: el reconocimiento del derecho al olvido. Revista chilena de Derecho y Tecnología, 4, 2, 215-261.

Novoa Monreal, E. (1989). Derecho a la vida privada y libertad de información. Un conflicto de derechos (4ª ed.). México: Siglo Veintiuno editores.

Prosser, W. (1960). Privacy. California Law Review, 48, 3, 383-423.

Rainer, A.; Martínez, J. \& Zúñiga, F. (2012). El principio de proporcionalidad en la jurisprudencia del Tribunal Constitucional. Estudios Constitucionales, 10, 1, 65-116.

Rossen, J. (2012). The right to be forgotten. Stanford Law Review, 64, 88-92.

Schwartz, P. (2013). The EU-U.S. privacy collision: A turn to institutions and procedures. Harvard Law Review 126, 1966-2009.

Uicich, R. D. (1999). Los bancos de datos y el derecho a la intimidad. Buenos Aires: Ad-Hoc.

Warren, S. \& Brandeis, L. (1890). The right to the privacy. Harvard Law Review 4, 54, 193-220. 